\title{
Issuing the Antibiotics for Children with and without Prescription in Pharmacies in Republic of Macedonia
}

\author{
Bistra Angelovska, Elena Drakalska, Marija Atanasova, Vesna Kostic and Jasmina Trajkoska \\ University “GoceDelcev”, Faculty of Medical Sciences, Krste Misirkov bb, POB 201, Stip, R. Macedonia
}

\begin{abstract}
The use of medicines for infants and children is presenting one unique set of challenges, because children are the most vulnerable population in any society. In this study, we set out to present the characteristics and classification of antibiotics recommended for children according to WHO, EMA and EBM. Also, the aim of this study was to analyze the most prescribed pediatric antibiotics in 2013 in Republic of Macedonia compared with standard treatments. Presented data was collected according to the number of prescribed recipes of pediatric dosage forms covered by the Fund of Republic of Macedonia. The obtained results showed that the most prescribed pediatric antibiotic is amoxicillin with clavulanic acid $(875 \mathrm{mg}+125 \mathrm{mg})$ in form of tablet, with 280863 prescribed recipes which corresponds to the recommendations of EBM.
\end{abstract}

Key words: Antibiotic, WHO, recipes, children.

\section{Introduction}

The use of medicines for infants and children is presenting one unique set of challenges for doctors, day by day, because children are the most vulnerable population in any society $[1,2]$. In contrast to adults, absorption, distribution, metabolism and excretion of drugs in infants and children can be very different $[3,4]$. In Republic of Macedonia and also worldwide, the problem with AMR (antimicrobial resistance) is enormous for healthcare services and communities [5, 6]. This major problem is associated with complicated treatments, extra costs of therapy and longer hospitalization with increased mortality risks [7, 8]. Generally, antibiotics are usually prescribed in primary healthcare organizations, commonly for viral diseases such as flu, cold etc., which results with non-effective treatment and increased risk of antimicrobial resistance [9-11]. Also, irrational use can be connected with consumption of antibiotics from previous treatment courses or issued by pharmacist without prescription [12]. According to National regulation in Republic of Macedonia, antibiotics can be purchased from

Corresponding author: Bistra Angelovska, professor, Ph.D., research field: medical. pharmacies only with prescription. However, different surveys showed significant abuse of antibiotics in Republic of Macedonia, related to increased OTC sale of antibiotics despite the law existence [12, 13]. Compared with other Balkan countries, one pilot study presented that citizens in Republic of Macedonia had the highest readiness for self-medication $[14,15]$.

The aim of this study is to present the characteristics and classification of antibiotics recommended for children, according to WHO, EMA and EBM, pediatric dosage forms registered in Republic of Macedonia and also the most prescribed antibiotics for children in 2013 in Republic of Macedonia compared with standard treatment methods.

\section{Methods}

\subsection{Data Analysis}

The first step in data analysis refers to selection and evaluation of pediatric drug formulations, classified according to route of administration and if they are included at reimbursement list of National Fund of Health insurance represented in tabular form (Table 1). Analyzed pediatric dosage formulations were obtained from the Register of medicinal products in Republic of 
Table 1 Pediatric antibiotics registered in Republic of Macedonia.

\begin{tabular}{|c|c|c|c|}
\hline ATC code & Generic name & Dosage form & Reimbursement list \\
\hline JO1CA01 & Ampicillin & Injection & Yes \\
\hline JO1CA01 & Ampicillin & Caps/Tabl. & No \\
\hline JO1CA01 & Ampicillin & Suspension & No \\
\hline JO1CA04 & Amoxicillin & Caps/Tabl & Yes \\
\hline J01CA04 & Amoxicillin & Suspension & Yes \\
\hline 01CR01 & Ampicillin + Sulbactam & Injection & Yes \\
\hline J01CR02 & Amoxicillin + clavulanic acid & Tablets & Yes \\
\hline J01CR02 & Amoxicillin + clavulanic acid & Suspension & Yes \\
\hline J01CE10 & Benzathine phenoxyme-thylpenicillin & Tablets & Yes \\
\hline J01CE10 & Benzathine phenoxy-methylpenicillin & Suspension & Yes \\
\hline J01DB01 & Cefalexin & Capsules & Yes \\
\hline J01DB01 & Cefalexin & Suspension & Yes \\
\hline J01DB05 & Cefadroxil & Capsules & Yes \\
\hline J01DB05 & Cefadroxil & Suspension & Yes \\
\hline J01DC04 & Cefaclor & Capsules & Yes \\
\hline J01DC04 & Cefaclor & Suspension & Yes \\
\hline J01DH02 & Meropenem & Inection & Yes \\
\hline J01EE01 & Sulfametxazole + trimethroprim & Tablets & Yes \\
\hline J01EE01 & Sulfametxozole + trimethroprim & Suspension & Yes \\
\hline J01EE03 & Sulfametrole + trimethoprim & Tablets & Yes \\
\hline J01EE03 & Sulfametrole + trimethoprim & Suspension & Yes \\
\hline J01FA01 & Erythromycin & Caps/Tabl & Yes \\
\hline J01FA09 & Clarithromycin & Tabl/Susp & Yes \\
\hline J01FA09 & Clarithromycin & Suspension & Yes \\
\hline J01FA10 & Azithromycin & Tabl/Caps & Yes \\
\hline J01FA10 & Azithromycin & Suspension & Yes \\
\hline J01FA10 & Azithromycin & Injection & Yes \\
\hline J01FF01 & Clindamycin & Capsules & Yes \\
\hline J01FF01 & Clindamycin & Injection & Yes \\
\hline J01FF02 & Lincomycin & Capsules & Yes \\
\hline J01FF02 & Lincomycin & Injection & Yes \\
\hline J01GB03 & Gentamicin & Injection & Yes \\
\hline J01MA01 & Oflaxin & Tablets & No \\
\hline J01MA02 & Ciprofloxacin & Tablets & Yes \\
\hline J01MA02 & Ciprofloxacin & Injection & Yes \\
\hline J01MA12 & Levofloxacin & Infusion & No \\
\hline J01AA02 & Doxycycline & Capsules & Yes \\
\hline J01XE01 & Nitrofurantoin & Solid capsules & No \\
\hline J0XA01 & Vancomycin & Injection & Yes \\
\hline
\end{tabular}

Macedonia, published on official website of Macedonian agency of medicines and medical devices.

After the classification and evaluation, the second step was data summarization. Data were collected through a number of prescribed recipes covered by the Fund in Republic of Macedonia. The study covered recipes of prescribed antibiotics intended for children aged 0-15 years in 2013 carried out in all cities in
Republic of Macedonia. Recipes were obtained from Ministry of health, summarized in tabular form and compared with the recommendations of WHO, EMA and EBM (Table 2).

\section{Results and Discussion}

In the Register of medicinal products in Republic of Macedonia, 39 dosage forms belong to antibiotics for 
Pharmacies in Republic of Macedonia

children from 19 INN, with determined prescribing regime and issuance. $92 \%$ of them are at reimbursement list of Fund of Health insurance. According to prescribing regime, $83 \%$ of pediatric antibiotics are prescribed in primary healthcare organizations, 5\% with specialist recommendation, while $12 \%$ belong to antibiotics for parenteral administration [16].

The registered pediatric antibiotics in Republic of Macedonia, classified according to the prescribing regime are represented in Table 1.

According to registered pediatric dosage formulations, represented in Table 1, unfortunately ampicillin is not covered by the National Fund of Health

Table 2 Number of recipes of prescribed pediatric antibiotics in 2013.

\begin{tabular}{|c|c|}
\hline Generic name and dosage form & Number of recipes \\
\hline Amoxicillin caps. $250 \mathrm{mg}$ & 8.457 \\
\hline Amoxicillin susp. $250 \mathrm{mg} / 5 \mathrm{ml}$ & 77.992 \\
\hline Amoxicillin + clavulanic acid tabl./fct. $(250 \mathrm{mg}+125 \mathrm{mg})$ & 171 \\
\hline Amoxicillin + clavulanic acid tabl./fct. $500 \mathrm{mg}$ & 40.842 \\
\hline Amoxicillin + clavulanic acid susp. $(125 \mathrm{mg}+31,5 \mathrm{mg})$ & 14.986 \\
\hline Amoxicillin + clavulanic acid susp. $(250 \mathrm{mg}+62,5 \mathrm{mg})$ & 8.557 \\
\hline Amoxicillin + clavulanic acid susp. (400 mg + 57 mg) & 130.961 \\
\hline Amoxicillin + clavulanic acid tabl./fct. $(875 \mathrm{mg}+125 \mathrm{mg})$ & 280.863 \\
\hline Amoxicillin caps. $500 \mathrm{mg}$ & 106.626 \\
\hline Azithromycin caps. $250 \mathrm{mg}$ & 7.976 \\
\hline Azithromycin susp. $100 \mathrm{mg} / 5 \mathrm{ml}$ & 5.109 \\
\hline Azithromycin susp. $200 \mathrm{mg} / 5 \mathrm{ml}$ & 8.564 \\
\hline Benzathinephenoxymethylpenicillin susp. 750.000 IU & 31.664 \\
\hline Cefaclor caps. $500 \mathrm{mg}$ & 8.940 \\
\hline Cefaclor caps. $250 \mathrm{mg}$ & 1 \\
\hline Cefaclor susp. $250 \mathrm{mg} / 5 \mathrm{ml}$ & 30.628 \\
\hline Cefaclor susp. $125 \mathrm{mg} / 5 \mathrm{ml}$ & 23.037 \\
\hline Cefadroxil caps. $500 \mathrm{mg}$ & 16.793 \\
\hline Cefadroxil susp. $250 \mathrm{mg} / 5 \mathrm{ml}$ & 32.640 \\
\hline Cefalexin caps. $250 \mathrm{mg}$ & 1.902 \\
\hline Cefalexin caps. $500 \mathrm{mg}$ & 129.782 \\
\hline Cefalexin susp. $250 \mathrm{mg} / 5 \mathrm{ml}$ & 58.638 \\
\hline Cefixime susp.100mg/5ml & 13.307 \\
\hline Cefixime tabl. $400 \mathrm{mg}$ & 40.209 \\
\hline Cefuroxime tabl. $125 \mathrm{mg}$ & 6.805 \\
\hline Cefuroxime tabl.250 mg & 24.423 \\
\hline Cefuroxime tabl. $500 \mathrm{mg}$ & 80.677 \\
\hline Ciprofloxacin tabl./fct. $250 \mathrm{mg}$ & 1.371 \\
\hline Ciprofloxacin fct. $500 \mathrm{mg}$ & 209.603 \\
\hline Clarithromycin fct. $500 \mathrm{mg}$ & 34.706 \\
\hline Clarithromycin caps. / fct. $250 \mathrm{mg}$ & 5.193 \\
\hline Clarithromycin susp. $125 \mathrm{mg} / 5 \mathrm{ml}$ & 11.202 \\
\hline Clarithromycin tabl.mod.rel. $500 \mathrm{mg}$ & 2.069 \\
\hline Erythromycin tabl. /fct. /caps. $250 \mathrm{mg}$ & 6.291 \\
\hline Erythromycin fct. 500mg & 380 \\
\hline Sulfamethoxazole + trimethoprim susp. $(200+40) \mathrm{mg}$ & 9.885 \\
\hline Sulfamethoxazole + trimethoprim tabl. $(100+20) \mathrm{mg}$ & 3 \\
\hline Sulfametrole + trimethoprim susp. $(200+40) \mathrm{mg}$ & 12.833 \\
\hline Sulfametrole + trimethoprim tabl. $(100+20) \mathrm{mg}$ & 658 \\
\hline
\end{tabular}


Insurance despite the lower incidence of side effects in comparison with amoxicillin with clavulanic acid as first treatment choice [17].

Azithromycin, clarithromycin, doxycycline and trimethoprim with sulfamethoxazole are covered by the National Fund without limitations in prescribing regime which is contrary to recommendations according to WHO and EBM [18].

Regarding the second step, the most commonly prescribed antibiotics in 2013, covered by the Fund of Republic of Macedonia intended for children aged 0-15 years, are represented in Table 2 .

The obtained results from the performed research showed that the most commonly prescribed antibiotic in 2013 is amoxicillin with clavulanic acid $(875 \mathrm{mg}+$ $125 \mathrm{mg}$ ) in form of tablet, with 280863 prescribed recipes. Ciprofloxacin $500 \mathrm{mg}$ tablet is represented with slightly fewer prescriptions 209 603, while the prescribed recipes for amoxicillin with clavulanic acid suspension are 130961 . Other antibiotics covered by the Fund, object of this study, are represented with number of prescribed recipes in range of 1200-100000 (Table 2) [19].

Most prescribed antibiotics for pediatric use represented in Table 2 from 2013 in Republic of Macedonia are according to recommendations of WHO [20]. Cephalexin and cefuroxime are most widely used cephalosporin antibiotics according to the performed survey. However, cefuroxime is not recommended by EBM [21].

In Republic of Macedonia there are guidelines for pediatric antibiotic prescribing related to EBM (Evidence-based medicine). Only 6 antibiotics (INN) from 19 registered are recommended according to these guidelines.

Non-compliance with the recommendations of reimbursement is generally due to frequent and inconsistent regulation changes. Weak control mechanisms also play major role in inappropriate use of antibiotics.

\section{Conclusion}

According to the obtained results, the most prescribed pediatric antibiotic in 2013 is amoxicillin with clavulanic acid $(875 \mathrm{mg}+125 \mathrm{mg})$ in form of tablet, with 280863 prescribed recipes, which corresponds to recommendations of EBM. In contrast, the second most prescribed antibiotic Ciprofloxacin is not recommended according to WHO. Despite the regulation in Republic of Macedonia, self-medication is represented with relatively high percentage due to the availability of antibiotics without prescription and the inappropriate use, general lack of knowledge about mechanism of action of antibiotics, side effects and the emergence of resistance.

The situation could be improved by revising / updating the lists of medicines in accordance with applicable regulations, clear determination of priorities for rational antibiotic use, continuous education of health professionals and also amplification of control state mechanisms.

\section{References}

[1] World Health Organization. 2008. "Children Are Not Little Adults: Children's Health and the Environment "WHO Training Package for the Health Sector. Accessed July 19, 2008. http://www.who.int/ceh/capacity/Children_are_not_little_ adults.pdf.

[2] Hersh, A., Jackson, M., and Lauri, A. 2013. "Principles of Judicious Antibiotic Prescribing for Upper Respiratory Tract Infections in Pediatrics" American Academy of Pediatrics 132 (6): 1146-54.

[3] Kim, D., and Park, M. S. 1998. "Antibiotic Use at a Pediatric Age" Yonsei Medical Journal 39 (6): 595-603.

[4] Emergency Care Institute. 2013. "Sepsis PAEDIATRIC First Dose Empirical Parenteral Antibiotic Guideline v2.1" Clinical Excellence Commission. Accessed September, 2013.

http://www.ecinsw.com.au/sites/default/files/field/file/PA EDIATRIC\%20Antibiotics\%20and\%20Administration.p df

[5] European Centre for Disease Prevention and Control. 2010. “Antimicrobial resistance surveillance in Europe 2009". Annual Report of the European Antimicrobial Resistance Surveillance Network (EARS-Net). Accessed 2010. 


\section{Pharmacies in Republic of Macedonia}

http://ecdc.europa.eu/en/publications/Publications/10

[6] American Health Organization. 2011. "Annual Network Monitoring / Surveillance Resistance to Antibiotics 2009”. Washington, D.C., Pan. Accessed 10 April 2012. http://new.paho.org/hq/index.php?option=com_doc man\&task=doc_download\&gid=14877\&Itemid

[7] European Centre for Disease Prevention and Control (ECDC) and European Medicines Agency (EMEA). 2009. "ECDC/EMEA Joint Technical Report - The bacterial challenge: time to react". Stockholm. Accessed 10 April 2012.

http://www.emae.europa.eu/docs/en_GB/document_librar y/Report/2009/11WC500008770.pdf

[8] Birnbaum, D. 2003. "Resistance CCoA. Antimicrobial Resistance: A Deadly Burden No Country Can Afford to Ignore." Canada Communicable Disease Report 29 (18): $157-64$.

[9] Goossens, H., Ferech, M., Vander Stichele, R., and Elseviers, M. "ESAC Project Group. 2005. Outpatient Antibiotic Use in Europe and Association with Resistance: A Cross-National Database Study." Lancet 365: 579-87.

[10] Arroll, B., and Kenealy, T. 2000. "Antibiotics for the Common Cold." Cochrane Database Syst Rev. (2): CD000247.

[11] Del Mar, C. B., Glasziou, P. P., and Spinks, A. B. 2000. "Antibiotics for Sore Throat." Cochrane Database Syst Rev. (4): CD000023.

[12] Grigoryan, L., Haaijer-Ruskamp, F. M., and Burgerhof, J. G. 2006. "Self-Medication with Antimicrobial Drugs in Europe." Emerg Infect Dis. 12: 452-9.

[13] Markovic-Pekovic, V., and Grubisa, N. 2012. "Self-Medication with Antibiotics in the Republic of Srpska Community Pharmacies: Pharmacy Staff Behavior." Pharmacoepid Drug Saf. 21: 1130-2.

[14] Radosevic, N., Vlahovic-Palcevski, V., and Benko, R. 2009. "Attitudes towards Antimicrobial Drugs among
General Population in Croatia, Fyrom, Greece, Hungary, Serbia and Slovenia." Pharmacoepid Drug Saf. 18 (8): 691-6.

[15] Ivanovska, V., Zdravkovska, M., Bosevska, G., and Angelovska, B. 2013. "Antibiotics for Upper Respiratory Infections: Public Knowledge, Beliefs and Self-Medication in the Republic of Macedonia." Contributions Sec. Biol. Med. Sci. 34 (2): 60-70.

[16] Ministry of Health. 2015. "Registry of Medicinal Products." Accessed November 15, 2015. http://lekovi.zdravstvo.gov.mk/drugsregister/overview.

[17] World Health Organization. 2013. "4th WHO Model List of Essential Medicines for Children's.” Accessed October 15 , 2013. http://apps.who.int/iris/bitstream/10665/93143/1/EMLc_4 _eng.pdf?ua=1.

[18] Ministry of Health. 2012. "Evidence based medicine: Pediatrics. Sinusitis." Official Journal of Republic of Macedonia. Accessed December 2012. http://mz.gov.mk/wp-content/uploads/2013/01/6603-sinu zit-kaj-deca.pdf.

[19] Macedonian National Health Insurance Fund. 2013. "Medicinal products. Number of Prescribed Recipes for 2013." Accessed January 2013. http://www.fzo.org.mk/WBStorage/Files/Polugodishen $\%$ 20Izveshtaj\%20za\%20potrosuvacka\%20na\%20lekovi\%2 0vo\%20period\%2001-06\%202013\%20godina.pdf.

[20] World Health Organization. 2010. "WHO Model Formulary for Children" WHO Library Cataloguing-in-Publication Data. Accessed January 2013. http://www.who.int/selection_medicines/list/WMFc_201 0. pdf.

[21] Ministry of Health. 2013. "Evidence Based Medicine: Pediatrics. Pneumonia." Official Journal of Republic of Macedonia. Accessed February 2015. http://mz.gov.mk/wp-content/uploads/2013/01/6599-pnev monii-vo-detstvoto.pdf. 